\title{
Simulation and optimization of irrigation schedule for summer maize based on SWAP model in saline region
}

\author{
Yanxin Pan ${ }^{1}$, Chengfu Yuan ${ }^{2 *}$, Siyuan Jing ${ }^{1}$ \\ (1. National and Local Joint Engineering of Hydraulic Engineering Safety and Efficient Utilization of Laboratory on \\ Water Resources in Poyang Lake Basin, Nanchang Institute of Technology, Nanchang 330099, China; \\ 2. Jiangxi Water Resources Institute, Nanchang 330013, China)
}

\begin{abstract}
In order to explore the appropriate irrigation schedule for summer maize, a field experiment was conducted in 2013 in Lubotan of Shaanxi Province. Soil water content, soil salinity, soil hydraulic parameters, crop growth parameters and summer maize yield were measured in the experiment. The SWAP model was calibrated based on field experiment observation data in 2013. The SWAP model was used to simulate and optimize irrigation schedule for summer maize after calibration. The results showed that model simulation results of soil water content, soil salinity and summer maize yield agreed well with the measured values. The Root Mean Square Error (RMSE) and Mean Relative Error (MRE) were within the allowable error ranges. The RMSE values were all lower than $0.05 \mathrm{~cm}^{3} / \mathrm{cm}^{3}$ and the MRE values were lower than $15 \%$ in soil water content calibration. The RMSE values were all lower than $0.1 \mathrm{mg} / \mathrm{cm}^{3}$ and the MRE values were lower than $20 \%$ in soil salinity calibration. The RMSE and MRE values were $1299.6 \mathrm{~kg} / \mathrm{hm}^{2}$ and $15.26 \%$ in summer maize yield calibration. The model parameters suitable for the study area were obtained in calibration. The SWAP model could be used to simulate and optimize irrigation schedule for summer maize after calibration. The SWAP model was used to simulate soil water-salt balance, summer maize yield and water use efficiency under different irrigation schedules. The model simulation results for different irrigation schedules indicated that the optimal irrigation schedules of summer maize were three times each for jointing stage (July 5), heading stage (August 5) and grain filling stage (August 30) with irrigation amount of $128 \mathrm{~mm}, 128 \mathrm{~mm}$ and $96 \mathrm{~mm}$, respectively. The optimal irrigation quota was $352.0 \mathrm{~mm}$ for summer maize in the study area.
\end{abstract}

Keywords: SWAP model, summer maize, irrigation schedule, saline region, Lubotan

DOI: $10.25165 /$ j.ijabe.20201303.5218

Citation: Pan Y X, Yuan C F, Jing S Y. Simulation and optimization of irrigation schedule for summer maize based on SWAP model in saline region. Int J Agric \& Biol Eng, 2020; 13(3): 117-122.

\section{Introduction}

Soil salinization is one of the major problems in the world, which is also a major factor affecting the agricultural production and farmland ecological environment in the arid regions and semi-arid regions. According to relevant statistics, the area of soil salinization is up to $9.21 \times 10^{6} \mathrm{hm}^{2}$ in the arid region and semi-arid region, accounting for $6.62 \%$ of the total farmland in China. If the soil suffering soil salinization can be rationally utilized, it can greatly help the agricultural development in China ${ }^{[1-3]}$. Lubotan was once lakes and depressions in Fuping County and Pucheng County in Shaanxi Province. Being affected by the natural factors and man-made factors, as time went by, the salt contained in the soil was accumulated and finally reached a certain amount. In recent years, it was developed as farmlands. However, because Lubotan was a kind of bottomland, so the water drainage of the farmlands was not good. When the level of underground water got higher, soil salinization became worse and worse. Then finally most of the farmlands in Lubotan were harmed by soil salinization, which adversely affected the agricultural

\section{Received date: 2019-06-20 Accepted date: 2020-03-26}

Biographies: Yanxin Pan, PhD, Lecturer, research interests: the farmland drainage and water environment protection, Email: yanxinpanxaut@126.com; Siyuan Jing, Master, research interests: water-saving irrigation, Email: 1454576987@qq.com.

*Corresponding author: Chengfu Yuan, $\mathrm{PhD}$ candidate, Lecturer, research interests: agricultural soil and water environment and water-saving irrigation. Mailing address: Jiangxi Water Resources Institute, Nanchang 330013, China. Tel: +86-791-83847840, Email: cfyuan1989@163.com. production $^{[4-6]}$. In 1999, local departments made a series of measures (like land leveling and irrigation system completing) to develop and control the farmlands. After a deep development and control, Lubotan hasn't suffered large-area soil salinization in the last 10 years. Therefore, crops like maize, cotton and wheat are able to grow normally and healthily ${ }^{[7,8]}$. Today, irrigation of the farmlands is mainly flooding irrigation, which not only wastes water resources but also increases the level of underground water at Lubotan. If so, secondary soil salinization will be resulted in soil. Under this background, it is necessary to study the rules of soil water-salt movement and irrigation management measures. It is known that field experiment is a kind of feasible way to study the soil water-salt movement and crop irrigation management. However, a long-term field experiment always costs a lot and requires a long cycle. On the basis of field experiment, use a mathematics model to simulate soil water-salt movement and crop irrigation management, which is also an effective and economical study method ${ }^{[9-12]}$. The SWAP model is being widely used to simulate soil water-salt movement and crop irrigation management at arid regions or semi-arid regions around the world. Yang et al. ${ }^{[13]}$ simulated soil water-salt movement and irrigation system for spring wheat, whose irrigation is done by brackish water at the Yellow River Irrigated Area in Ningxia with SWAP model, and also evaluated and analyzed different irrigation schedule. Yang et al. ${ }^{[14]}$ established the regional soil water and salt movement model system based on the basis of field experiment and SWAP model and also simulated and perfected the soil salt balance and scheme of rotational irrigation by saline and fresh water at Hetao region of Inner Mongolia. Ma et al. ${ }^{[15]}$ simulated and optimized the 
rotational irrigation system of winter wheat-summer maize at different hydrological years and also simulated the groundwater recharge of optimization irrigation schedule in North China. Qureshi et al. ${ }^{[16]}$ calibrated and validated SWAP model based on the field experiment data and also made a comparative analysis of the relative yield of wheat and maize under different irrigation amounts at a project region in Iraq. By the comparative analysis, the wheat irrigation amount was $500 \mathrm{~mm}$ and the maize irrigation amount $600 \mathrm{~mm}$. This irrigation schedule was the optimal schedule for crop yield. There was no report about to simulate and perfect the crop irrigation schedule using SWAP model in Lubotan district of Shaanxi Province. For the study in this paper, the SWAP model parameters were calibrated based on the basis of field experiment of summer maize. The water-salt balance, summer maize yield and water use efficiency of different irrigation schedules were simulated by SWAP model. In this case, the optimal irrigation schedule can be obtained in the study area. This study could provide theoretical bases for the Lubotan district in terms of rational use of water resources and water-saved irrigation.

\section{Field experiment}

\subsection{General situation of the study region}

A field experiment was conducted at Lubotan district (located at the boundary of Fuping County and Pucheng County in Shaanxi Province, $109^{\circ} 22^{\prime} \mathrm{E}, 34^{\circ} 48^{\prime} \mathrm{N}$, altitude $490 \mathrm{~m}$ ) from June to September in 2013. The study area is a typical semi-arid continental climate. The average annual precipitation is $472.9 \mathrm{~mm}$ and the average annual evaporation is $1000-1300 \mathrm{~mm}$, which is 2 to 3 times of the average annual precipitation. Besides, the precipitation in one year is not evenly distributed, mainly precipitation from July to September. The precipitation is about $49 \%$ of the total precipitation from July to September. One standard agricultural farmland was selected as an experimental plot in Lubotan district and the area was $40000 \mathrm{~m}^{2}$ (the distance from north to south was $400 \mathrm{~m}$, the distance from east to west was $100 \mathrm{~m}$ ). The main tillage method was winter wheat and summer maize rotation. There was a lot of saline-alkali land in Lubotan district. The saline-alkali land was a kind of typical sulfate-alkali soil, which PH was 8.3. The experiment plot was silty soil (international system) in the depth of $0-100 \mathrm{~cm}$ soil layers. The particle size composition was as follows: sand $(0.05-1.00 \mathrm{~mm})$ accounted for $44.07 \%$ (volume fraction, the same below), silt $(0.005-0.05 \mathrm{~mm})$ accounted for $46.81 \%$, clay $(<0.005 \mathrm{~mm})$ accounted for $3.23 \%$ (measured by MS2000 laser particle size analyzer). The soil bulk density was $1.48 \mathrm{~g} / \mathrm{cm}^{3}$. The saturated water content was $0.44 \mathrm{~cm}^{3} / \mathrm{cm}^{3}$. The organic carbon content was $1.16 \%$. Summer maize (Zhengdan 958) was selected as the experiment crop, which was planted on June 10 while harvested on September 28 in 2013 and the growing period was $112 \mathrm{~d}$. The standard agricultural farmland was irrigated by flooding irrigation. The summer maize was irrigated for 4 times. The irrigation water quota as follows: $100 \mathrm{~mm}$ for seeding stage (June 25), $120 \mathrm{~mm}$ for jointing stage (July 15), $120 \mathrm{~mm}$ for heading period (August 22) and $100 \mathrm{~mm}$ for the filling stage (September 10). The irrigation water salinity was $0.4 \mathrm{~g} / \mathrm{L}$. During the experiment, the agricultural measures shall be carried out according to the local actual situation.

\subsection{Sampling methods}

Observation sections were arranged in the middle of standard agricultural farmland. 3 TRIME pipes (1 m long) were placed in the observation section. Soil water content was measured with
TRIME-PICO and taken the average value of three sampling sites. The soil samples were taken at a depth of $0-20 \mathrm{~cm}, 20-40 \mathrm{~cm}$, $40-60 \mathrm{~cm}, 60-80 \mathrm{~cm}$ and $80-100 \mathrm{~cm}$ by soil auger in the places around TRIME pipes and taken the average value of three soil sampling sites. Electrical conductivity, $\mathrm{EC}_{1: 5}(\mathrm{mS} / \mathrm{kg})$ was measured using SG-3 conductivity meter (SG3-ELK742) and translated into soil salinity $(\mathrm{g} / \mathrm{kg})$ by the equation $\left(S=0.2813 \mathrm{EC}_{1: 5^{-}}\right.$ 0.0056). There was a well $(3 \mathrm{~m})$ for observing the groundwater depth in the middle of standard agricultural farmland, in which the change of groundwater depth could be observed. The groundwater depth was changed from 1.85 to $2.25 \mathrm{~m}$ during the summer maize growing stage. Initial soil water content, soil salt content, soil physical parameters and soil hydraulic parameters at the depth of 0-100 cm were obtained before planting summer maize. Soil water characteristic curve parameters were measured by high-speed centrifuge (Hexi HR21M). VG (van Genuchten) model hydraulic parameters were obtained by using the software RETC. The soil hydraulic parameters as follows: residual water content was $\theta_{r}=0.0275 \mathrm{~cm}^{3} / \mathrm{cm}^{3}$, saturated water content was $\theta_{s}=0.4435 \mathrm{~cm}^{3} / \mathrm{cm}^{3}$, shape factor were $\alpha=0.089, n=1.574$ and $\gamma=0.5$. The saturated hydraulic conductivity was measured by soil permeability meter (TST-55, China) with constant head permeameter and $K_{s}=99.86 \mathrm{~cm} / \mathrm{d}$. The maize plant height, leaf length and width were measured by a steel tape every 7-10 d after maize seedling. The maize root length density was measured by a drilling method at different growth stages. After harvest, summer maize yield was measured. An automatic meteorological station was installed in the experimental station. Meteorological data downloaded and obtained from automatic meteorological station.

\section{SWAP model}

The SWAP model, developed by the Water Resource Group of Wageningen University, is a one-dimensional agricultural hydrological model that used to simulate vertical soil water flow, solute and heat transport and crop growth. It has been widely applied to simulate irrigation, soil water-salt transport, crop evapotranspiration, crop growth, drainage, and groundwater table in semi-arid and arid areas around the world. The calculation formula of this model as follows:

Richards' equation was used for soil water content movement:

$$
\frac{\partial \theta}{\partial t}=C(h) \frac{\partial h}{\partial t}=\frac{\partial}{\partial z}\left[K(h)\left(\frac{\partial h}{\partial z}+1\right)\right]-S(h)
$$

where, $\theta$ is soil water content, $\mathrm{cm}^{3} / \mathrm{cm}^{3} ; t$ is time, d; $C$ is differential water capacity, $\mathrm{cm} ; h$ is soil water pressure head, $\mathrm{cm} ; z$ is the vertical coordinate (positive uptake), $\mathrm{cm} ; K(\mathrm{~h})$ is the hydraulic conductivity, $\mathrm{cm} / \mathrm{d} ; S(h)$ is the soil water extraction rate by plant roots, $\mathrm{cm}^{3} /\left(\mathrm{cm}^{3} \cdot \mathrm{d}\right)$.

Convective dispersive equation was used for soil salt movement:

$$
J=q c-\theta\left(D_{d i f}+D_{d i s}\right) \frac{\partial c}{\partial z}
$$

where, $J$ is total solute flux density, $\mathrm{g} /\left(\mathrm{cm}^{2} \cdot \mathrm{d}\right) ; q$ is vertical flow at the bottom, $\mathrm{cm} / \mathrm{d} ; c$ is solute concentration in soil water, $\mathrm{g} / \mathrm{cm}^{3} ; D_{\text {dif }}$ is the diffusion coefficient, $\mathrm{cm}^{2} / \mathrm{d} ; \mathrm{D}_{\mathrm{dis}}$ is the dispersion coefficient, $\mathrm{cm}^{2} / \mathrm{d} ; \partial \mathrm{c} / \partial \mathrm{z}$ is the solute concentration gradient.

The SWAP model simulates crop growth process using WOFOST crop growth model, which includes a detailed crop model and a simple crop model. The simple crop growth module of Doorenbos and Kassam (1979) included in SWAP was used in this study ${ }^{[17]}$. The calculation formula of this model as follows: 


$$
1-\frac{Y_{a, k}}{Y_{p, k}}=K_{y, k}\left(1-\frac{T_{a, k}}{T_{p, k}}\right)
$$

where, $Y_{a, k}$ is the actual yield, $\mathrm{kg} / \mathrm{hm}^{2} ; Y_{p, k}$ is the potential yield, $\mathrm{kg} / \mathrm{hm}^{2} ; T_{a, k}$, is the actual transpiration, $\mathrm{cm} ; T_{p, k}$ is potential transpiration, $\mathrm{cm} ; K_{y, k}$ is the yield response factor of growing stage $k$. Index $k$ is the growing stage. The relative yield of the whole growing season as the product of the relative yield of each growing stage is calculated by:

$$
\frac{Y_{a}}{Y_{p}}=\sum_{k=1}^{n}\left(\frac{Y_{a, k}}{Y_{p, k}}\right)
$$

where, $Y_{a}, Y_{p}$ are the cumulative actual yield $\left(\mathrm{kg} / \mathrm{hm}^{2}\right)$ and the cumulative potential yield $\left(\mathrm{kg} / \mathrm{hm}^{2}\right)$ of the entire growing season, respectively; $n$ is the number of defined crop growing stages.

According to the actual situation of the soil and the root depth of summer maize, the soil layer at the depth of 0-100 was divided into 34 cells. In order to accurately calculate soil water content movement on the soil surface, the cell on the surface was $1 \mathrm{~cm}$ deep while the cells from the deeper soil were 2.5-5.0 cm deep. The measured parameters were required in SWAP model. The meteorological data was obtained from an automatic meteorological station. Irrigation data, crop growing data, soil physical and chemical parameters and hydraulic parameters were measured in the experiment. Upper boundary conditions of the model included rainfall, evaporation, plant transpiration and irrigation determined by the climate factors. The lower boundary condition was the change of underground water level along with the time. The soil water pressure head which was transformed from the initial soil water content. The soil water pressure head and the soil salinity before sowing was regard as the initial condition. Detailed introduction to the SWAP model can refer to the SWAP model theory book ${ }^{[18]}$. The RMSE and MRE values were used to quantify the deviation of the simulated and measured data.

\section{Results and analysis}

\subsection{Soil water content}

The SWAP model was calibrated using field experiments data, which includes soil water content, soil salinity, meteorological data, irrigation data, soil hydraulic parameters and crop parameters. The rationality of SWAP model was verified by comparing the simulation with the measured results. The soil water content at depths of 0-20 cm, 20-40 cm, 40-60 cm and $60-100 \mathrm{~cm}$ was used to calibrate the SWAP model in 2013. The results are shown in Figure 1. The simulated soil water content agreed reasonably well with the measured values at different soil layers. The simulated values efficiently reflected variation tendency of the measured data. The statistically evaluated result for soil water content is shown in Table 1. The RMSE and MRE values were less than $0.05 \mathrm{~cm}^{3} / \mathrm{cm}^{3}$ and $15 \%$ in model calibration. The statistically evaluated results demonstrated that model performance for soil water content simulation is good. The soil hydraulic parameters after calibration are shown in Table 2.
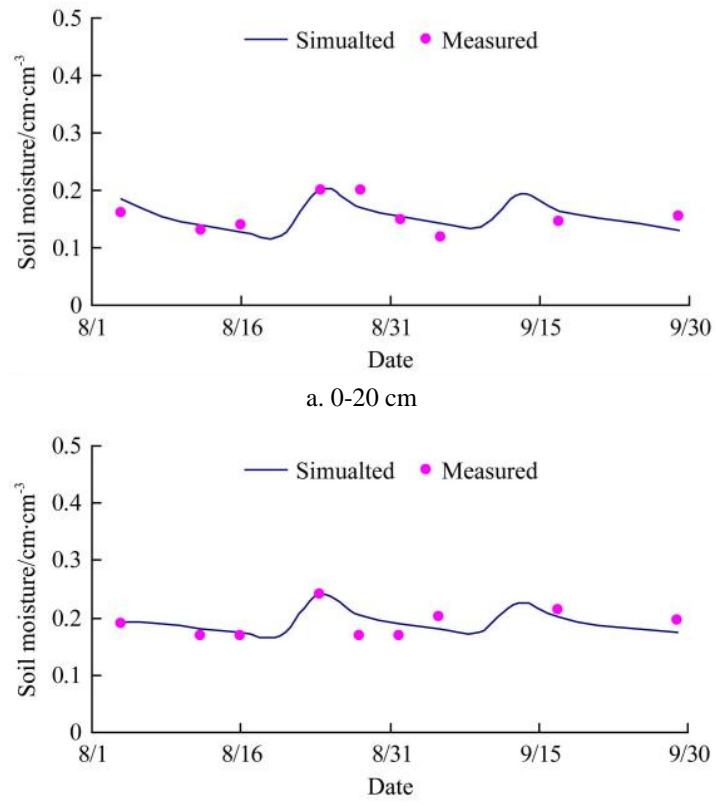

b. $20-40 \mathrm{~cm}$

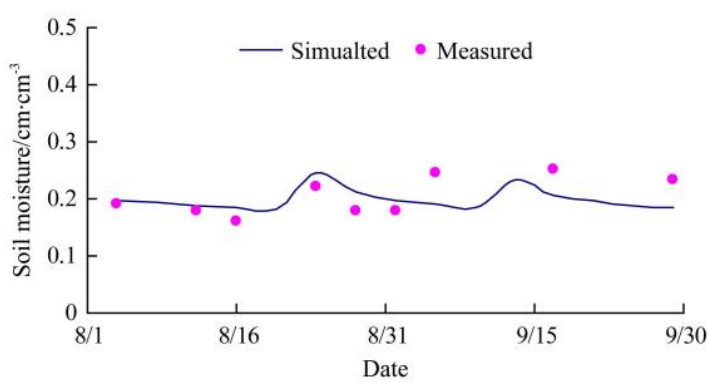

c. $40-60 \mathrm{~cm}$

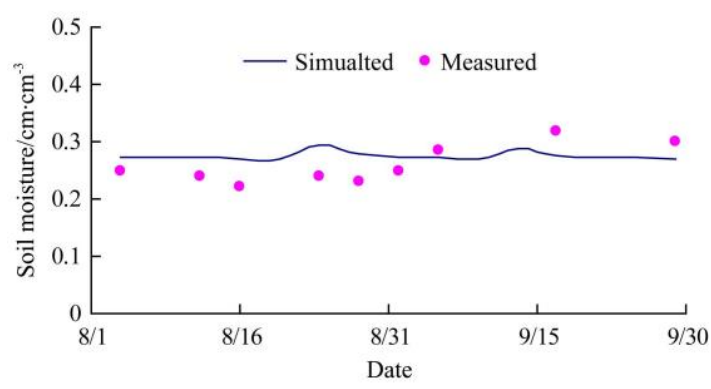

d. $60-100 \mathrm{~cm}$

Figure 1 Simulated and measured soil water content in calibration

Table 1 Statistically evaluated result for soil water content and soil salt concentration

\begin{tabular}{cccccc}
\hline \multirow{2}{*}{$\begin{array}{c}\text { Soil depth } \\
\text { /cm }\end{array}$} & \multicolumn{2}{c}{ Soil water content } & & \multicolumn{2}{c}{ Soil salt concentration } \\
\cline { 2 - 3 } \cline { 5 - 6 } & $\mathrm{RMSE} / \mathrm{cm}^{3} \cdot \mathrm{cm}^{-3}$ & $\mathrm{MRE} / \%$ & & $\mathrm{RMSE} / \mathrm{mg} \cdot \mathrm{cm}^{-3}$ & $\mathrm{MRE} / \%$ \\
\hline $0-20$ & 0.02 & 11.40 & 0.09 & 17.05 \\
$20-40$ & 0.02 & 7.87 & & 0.08 & 12.03 \\
$40-60$ & 0.04 & 13.86 & & 0.08 & 12.51 \\
$60-100$ & 0.04 & 14.01 & & 0.09 & 14.22 \\
\hline
\end{tabular}

Table 2 Soil hydraulic parameters and solute transport parameters after calibration

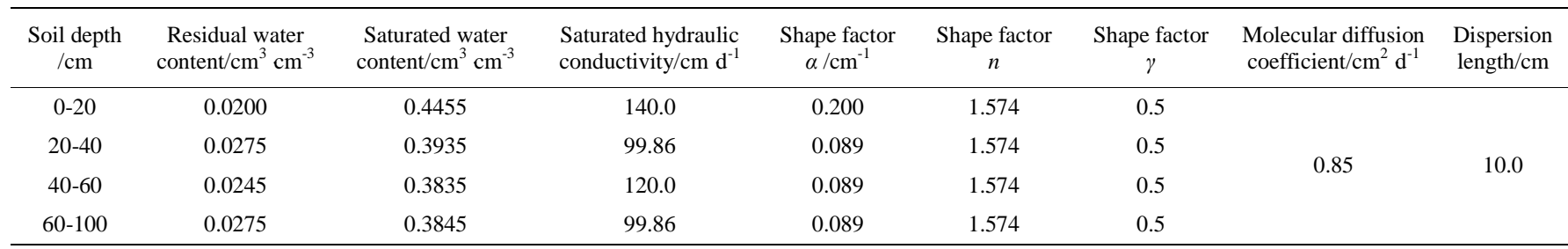




\subsection{Soil salt concentration}

The soil salt concentration at depths of $0-20 \mathrm{~cm}, 20-40 \mathrm{~cm}$, $40-60 \mathrm{~cm}$ and $60-100 \mathrm{~cm}$ was used to calibrate the SWAP model in 2013. The results are shown in Figure 2. From Figure 2, we can see that the simulated soil salt concentration agreed reasonably well with the measured values at different soil layers from August to September in 2013, which was not as good as the simulation of soil water content. However, the simulated soil salt concentration reflected the changing trend of measured value. The statistically evaluated result for soil salt concentration is shown in Table 1. The RMSE and MRE values were less than $0.1 \mathrm{mg} / \mathrm{cm}^{3}$ and $20 \%$ in model calibration, which within the allowable error range $(25 \%)$. The statistically evaluated results demonstrated that model performance for soil salt concentration simulation is good. The dispersion length and molecular diffusion coefficient after calibration are shown in Table 2.
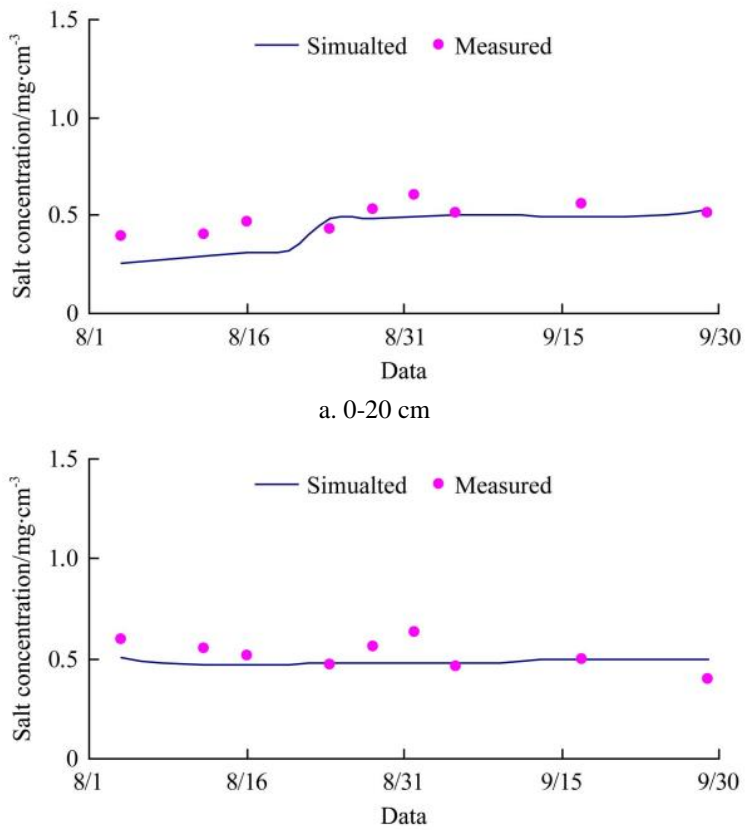

b. $20-40 \mathrm{~cm}$

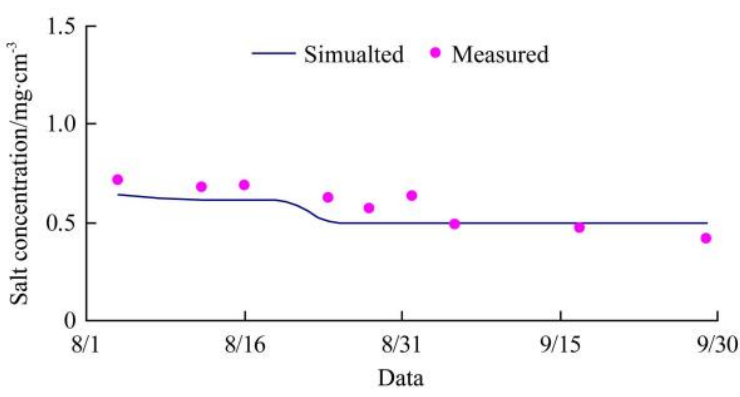

c. $40-60 \mathrm{~cm}$

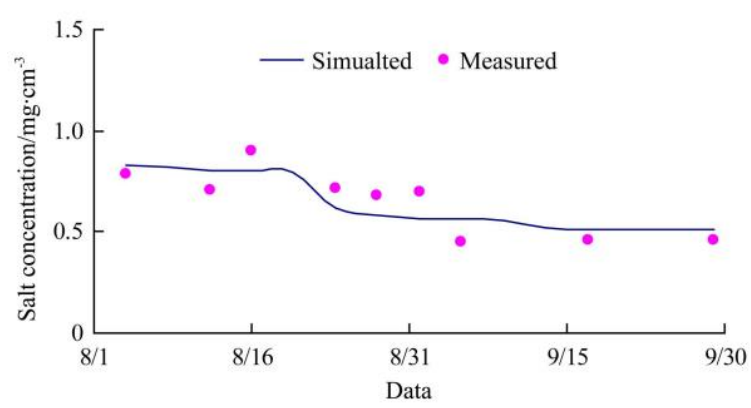

d. $60-100 \mathrm{~cm}$

Figure 2 Simulated and measured soil salt concentration in calibration

\subsection{Summer maize yield}

The simulated yield of summer maize was relative yield in SWAP model. The relative yield of summer maize was 0.80 in this experiment field. The average yield of summer maize was $9021 \mathrm{~kg} / \mathrm{hm}^{2}$ at Guanzhong District in Shaanxi Province ${ }^{[19]}$. It assumed that the relative yield of summer maize was 1.0 in Guanzhong District. Then it was figured out that the simulated yield was $7216.8 \mathrm{~kg} / \mathrm{hm}^{2}$ by the simulated relative yield. The measured yield of summer maize was $8516.4 \mathrm{~kg} / \mathrm{hm}^{2}$ in the field experiment. The RMSE value was $1299.6 \mathrm{~kg} / \mathrm{hm}^{2}$ and the MRE value was $15.26 \%$, which within the allowable error range (25\%). Calibrated parameters in crop modules of summer maize are shown in Table 3. It was concluded that the SWAP model was able to simulate the yield of summer maize in Lubotan District of Shaanxi Province.

Table 3 Calibrated parameters in crop modules of summer maize

\begin{tabular}{lc}
\hline \multicolumn{1}{c}{ Model parameters } & Summer maize \\
\hline Start to extract water from the soil/cm & -15 \\
Start to extract water optimally from the upper soil layer/cm & -30 \\
Start to extract water optimally from all lower soil layers/cm & -30 \\
Cannot extract water optimally anymore in case of high & -325 \\
atmospheric demand/cm & \\
Cannot extract water optimally anymore in case of low & -800 \\
atmospheric demand/cm & -10000 \\
Cannot take up water anymore (wilting point)/cm & 60 \\
Minimum canopy resistance/(s- $\mathrm{m}^{-1}$ ) & 0.25 \\
Precipitation interception coefficient & 4.0 \\
ECsat level below which no salt stress $/\left(\mathrm{dS} \cdot \mathrm{m}^{-1}\right)$ & 10.0 \\
Decline rootwater uptake above this level/\% &
\end{tabular}

Based on the above model calibration results, it demonstrates that the calibrated SWAP model was able to simulate soil water-salt transport and summer maize yield. It can be used to study the simulation and optimization of the summer maize irrigation schedule.

\subsection{Simulation and optimization of summer maize under different irrigation schedules}

Flooding irrigation was used to irrigate the summer maize at Lubotan of Shanxi Province. It was a kind of rough irrigation and it wasted a lot of water, which was also easy to result in secondary salinization to the soil. The research area was located in the semi-arid and semi-wet zone, which average annual rainfall is only $472.9 \mathrm{~mm}$. It was a water resource shortage. Agricultural production requires large amounts of water in this research area. Under this background, it was necessary to use water saving irrigation measures to further improve the unreasonable utilization of water resources and achieve sustainable utilization of water resources. It was an effective water-saving irrigation method to adjust and optimize crop irrigation quota appropriately to achieve saving irrigation. The calibrated SWAP model was used to simulate and optimize the irrigation scheme of summer maize in the study region, in order to explore the suitable irrigation schedule for summer maize. The rainfall was $192.2 \mathrm{~mm}$ during the growing stage of summer maize in 2013. The simulation meteorological data used the meteorological data in 2013. The total irrigation water quota of local summer maize was $440 \mathrm{~mm}$ in the study area. The irrigation water quantity was $100 \%, 80 \%$, $60 \%$ and $50 \%$ of the local irrigation quota in model simulation. The irrigation water quantity was $440 \mathrm{~mm}, 352 \mathrm{~mm}, 264 \mathrm{~mm}$ and $220 \mathrm{~mm}$, respectively. According to the local irrigation 
experience, the irrigation could be done for 4 times or 3 times during the summer maize growing stage. If the irrigation was done for 4 times, the irrigation data could refer to an experiment in 2013. That was that the irrigation could be done on June 25 (seeding stage), July 15 (jointing stage), August 22 (heading stage) and September 10 (filling stage). If the irrigation was done for 3 times, it could be done on July 5 (joint stage), August 5 (heading stage) and August 30 (filling stage). According to the distribution proportion of summer maize each growth stage, the irrigation water quota of each growth stage was determined under different irrigation levels. Different irrigation schedules for summer maize are shown in Table 4.

Table 4 Different irrigation schedules for summer maize

\begin{tabular}{|c|c|c|c|c|c|c|}
\hline \multirow{2}{*}{$\begin{array}{l}\text { Irrigation } \\
\text { times }\end{array}$} & \multirow{2}{*}{$\begin{array}{l}\text { Irrigation } \\
\text { scheme } \\
/ \mathrm{mm}\end{array}$} & \multirow{2}{*}{$\begin{array}{c}\text { Total } \\
\text { irrigation } \\
\text { water } \\
\text { quota } / \mathrm{mm}\end{array}$} & \multicolumn{4}{|c|}{ irrigation water quota/mm } \\
\hline & & & $\begin{array}{l}\text { Seeding } \\
\text { stage }\end{array}$ & $\begin{array}{l}\text { Jointing } \\
\text { stage }\end{array}$ & $\begin{array}{l}\text { Heading } \\
\text { stage }\end{array}$ & $\begin{array}{l}\text { Filling } \\
\text { stage }\end{array}$ \\
\hline \multirow{4}{*}{4 times } & 1 & 440.0 & 100 & 120 & 120 & 100 \\
\hline & 2 & 352.0 & 80 & 96 & 96 & 80 \\
\hline & 3 & 264.0 & 60 & 72 & 72 & 60 \\
\hline & 4 & 220.0 & 50 & 60 & 60 & 50 \\
\hline \multirow{4}{*}{3 times } & 5 & 440.0 & 0 & 160 & 160 & 120 \\
\hline & 6 & 352.0 & 0 & 128 & 128 & 96 \\
\hline & 7 & 264.0 & 0 & 96 & 96 & 72 \\
\hline & 8 & 220.0 & 0 & 80 & 80 & 60 \\
\hline
\end{tabular}

The initial soil water content, soil salt concentration, growth parameters of summer maize were consistent with the measured data of the experiment in 2013, other boundary conditions were also the same. The simulation soil was $0-100 \mathrm{~cm}$ depth. The calibrated SWAP model was used to simulate these 8 irrigation schemes. The simulation results were shown in Table 5. We could see that soil water change, water and salt flux at the bottom of 0-100 cm layer, evapotranspiration, summer maize yield and water use efficiency decreased with the decrease in irrigation water quota and soil salt accumulation increased with the decrease in irrigation water quota. When selecting the irrigation schedule, focus on the standard that summer maize yield and water use efficiency were higher, irrigation water quota and soil salt increase were less. The irrigation was conducted four times. The increase of soil salinity in irrigation scheme 2 was less and the leaching soil salinity was $0.40 \mathrm{mg} / \mathrm{cm}^{2}$, which would not cause the continuous accumulation of soil salinity in $0-100 \mathrm{~cm}$ soil layer. The summer maize yield was $7126.59 \mathrm{~kg} / \mathrm{hm}^{2}$ and the water use efficiency was $1.537 \mathrm{~kg} / \mathrm{m}^{3}$. Higher summer maize yield, water use efficiency and less increase of soil salinity can be obtained compared with other irrigation schemes. Therefore, irrigation scheme 2 was the best irrigation scheme for four times of irrigation. The irrigation was conducted three times. The increase of soil salinity in irrigation scheme 6 was less and the leaching soil salinity was $0.21 \mathrm{mg} / \mathrm{cm}^{2}$, which would not cause the continuous accumulation of soil salinity in $0-100 \mathrm{~cm}$ soil layer. The summer maize yield was $7758.06 \mathrm{~kg} / \mathrm{hm}^{2}$ and the water use efficiency was $1.555 \mathrm{~kg} / \mathrm{m}^{3}$. Higher summer maize yield, water use efficiency and less increase of soil salinity can be obtained compared with other irrigation schemes. Therefore, irrigation scheme 6 was the best irrigation scheme three times irrigation. Comparing irrigation scheme 2 with irrigation scheme 6 , it can be seen that the yield and water use efficiency of irrigation scheme 6 were higher than irrigation scheme 2 under the condition that soil salinity was leached. Irrigation scheme 6 was an optimal irrigation scheme for summer maize in the study area. The optimal irrigation schedules of summer maize were three times each for jointing stage (July 5), heading stage (August 5) and grain filling stage (August 30) with irrigation amount of $128 \mathrm{~mm}, 128 \mathrm{~mm}$ and $96 \mathrm{~mm}$, respectively. The optimal irrigation quota was $352.0 \mathrm{~mm}$ for summer maize in the study region.

Table 5 Simulation results of different irrigation schedules

\begin{tabular}{|c|c|c|c|c|c|c|c|c|c|c|}
\hline \multirow{2}{*}{$\begin{array}{l}\text { Irrigation } \\
\text { scheme }\end{array}$} & \multicolumn{5}{|c|}{ Analysis of water balance } & \multicolumn{3}{|c|}{ Analysis of salt balance } & \multirow{2}{*}{$\begin{array}{c}\text { Yield } \\
/ \mathrm{kg} \cdot \mathrm{hm}^{-2}\end{array}$} & \multirow{2}{*}{$\begin{array}{l}\text { Water use } \\
\text { efficiency } \\
\quad / \mathrm{kg} \cdot \mathrm{m}^{-3}\end{array}$} \\
\hline & $\begin{array}{l}\text { Irrigation } \\
/ \mathrm{mm}\end{array}$ & $\begin{array}{c}\text { Rainfall and } \\
\text { interception/mm }\end{array}$ & $\begin{array}{l}\text { Soil water } \\
\text { change/mm }\end{array}$ & $\begin{array}{l}\text { Bottom } \\
\text { flux/mm }\end{array}$ & $\mathrm{ET} / \mathrm{mm}$ & $\begin{array}{l}\text { From irrigation } \\
\qquad / \mathrm{mg} \cdot \mathrm{cm}^{-2}\end{array}$ & $\begin{array}{l}\text { Bottom flux } \\
/ \mathrm{mg} \cdot \mathrm{cm}^{-2}\end{array}$ & $\begin{array}{l}\text { Increase in } \\
\text { soil } / \mathrm{mg} \cdot \mathrm{cm}^{-2}\end{array}$ & & \\
\hline 1 & 440.0 & 176.5 & -19.1 & -171.0 & 464.6 & 22.00 & -25.32 & -3.32 & 7216.80 & 1.553 \\
\hline 2 & 352.0 & 176.5 & -56.0 & -120.8 & 463.7 & 17.60 & -18.00 & -0.40 & 7126.59 & 1.537 \\
\hline 3 & 264.0 & 176.5 & -74.3 & -76.7 & 438.1 & 13.20 & -11.31 & 1.89 & 6585.33 & 1.503 \\
\hline 5 & 440.0 & 176.5 & -66.2 & -183.0 & 499.7 & 22.00 & -26.89 & -4.89 & 7848.27 & 1.571 \\
\hline 6 & 352.0 & 176.5 & -88.4 & -118.1 & 498.8 & 17.60 & -17.81 & -0.21 & 7758.06 & 1.555 \\
\hline 7 & 264.0 & 176.5 & -97.7 & -56.9 & 481.3 & 13.20 & -8.23 & 4.97 & 7397.22 & 1.537 \\
\hline 8 & 220.0 & 176.5 & -101.6 & -41.0 & 457.1 & 11.00 & -5.80 & 5.20 & 6765.75 & 1.480 \\
\hline
\end{tabular}

Note: The soil water change was a negative value, which meant soil water was consumed; the bottom flux was a negative value, which meant soil water went downward; soil salt bottom flux was a negative value, which meant salt went downward; the increase of soil salt was a negative value, which meant soil salt was leached.

\section{Conclusions}

A field experiment was conducted on one of standard agricultural farmland in Lubotan area of Shaanxi Province and the SWAP model was calibrated based on field experimental observation data. The SWAP model was used to simulate and optimize irrigation schedule for summer maize after calibration. The following conclusions can be drawn from this study:

(1) Calibration results of the SWAP parameters showed that soil water content, soil salt content and summer maize yield agreed well with the measured values. The RMSE and the MRE were within the allowable error area. The RMSE values were all lower than $0.05 \mathrm{~cm}^{3} / \mathrm{cm}^{3}$ and the MRE values were lower than $15 \%$ in soil water content calibration. The RMSE values were all lower than $0.1 \mathrm{mg} / \mathrm{cm}^{3}$ and the MRE values were lower than $20 \%$ in soil salinity calibration. The RMSE and MRE values were $1299.6 \mathrm{~kg} / \mathrm{hm}^{2}$ and $15.26 \%$ in summer maize yield calibration. The SWAP model parameters were obtained after calibration. The calibrated SWAP model was able to be used for the simulation and optimization irrigation schedule of summer maize.

(2) The SWAP model simulation results for different irrigation schedules indicated that the optimal irrigation schedules of summer 
maize were three times each for jointing stage (July 5), heading stage (August 5) and grain filling stage (August 30) with irrigation amount of $128 \mathrm{~mm}, 128 \mathrm{~mm}$ and $96 \mathrm{~mm}$, respectively. The optimal irrigation quota was $352.0 \mathrm{~mm}$ for summer maize. It was an optimal irrigation schedule for the summer maize in the research area. The optimal irrigation schedule for summer maize needs further verification and improvement in production practice in the study region.

\section{Acknowledgements}

This research was financially supported by Jiangxi Educational Bureau Science-Technology Research Program (GJJ170981), National Natural Science Foundation of China (51709144), and Farmland Irrigation Research Institute, Chinese Academy of Agricultural Sciences (FIRI2017-22-01).

\section{[References]}

[1] Metternicht G I, Zinck J A. Remote sensing of soil salinity: Potentials and constraints. Remote Sensing of Environment, 2003; 85(1): 1-20.

[2] Yang J S. Development and prospect of the research on salt-affected soils in china. Acta Pedologica Sinica, 2008; 5: 837-845.

[3] Zhou $\mathrm{Z}$ M, Zhao $\mathrm{S} \mathrm{H}$. Influencing factors on surface soil salt accumulation the semi-arid North China Plain. Arid Land Geography, 2015; 38(5): 976-984. (in Chinese)

[4] Pan Y X, Luo W, Jia Z H, Li J, Chen Y. Experiment on salt exchange between sediments and ponding water in drainage ditches of saline farmland. Transactions of the CSAE, 2013; 29(2): 81-87. (in Chinese)

[5] Quan Q, Xie J C, Shen B, Luo W. Soil sampling method based on field measurements and remote sensing images. Transactions of the CSAE, 2010; 26(12): 237-241. (in Chinese)

[6] Pan Y X, Luo W, Jia Z H, Jing S Y, Li S, Wu D. Experimental study on measuring soil water content with TRIME-T3 in a saline environment. Arid Land Geography, 2017; 40(1): 108-113. (in Chinese)

[7] Pan Y X, Luo W, Jia Z H, Jing S Y, Li S, Wu D. The simulation of water and salt transportation by HYDRUS model in Lubotan of Shaanxi, China. Agricultural Research in the Arid Areas, 2017; 35(1): 135-142. (in Chinese)

[8] Han W C. Study and practice report about comprehensive governance and harmonious ecological environment model for salt-alkaline land at Lubotan District, Shaanxi. Shaanxi: Shaanxi Provincial Land Engineering Construction Group, 2008.

[9] Xu X, Huang G H, Zhan H B, Qu Z Y, Huang Q Z. Integration of SWAP and MODFLOW-2000 for modeling groundwater dynamics in shallow water table areas. Journal of Hydrology, 2012; 412-413: 170-181.

[10] Ma Y, Feng S Y, Huo Z L, Song X F. Application of the SWAP model to simulate the field water cycle under deficit irrigation in Beijing. Mathematical and Computer Modelling, 2011; 54: 1044-1052.

[11] Sheng Y, Zhao C Y, Jia H T. Effects of Water and Fertilizer Coupling on Soil Moisture Movement in Corn Fields. Arid Land Geography, 2005; 28(6): 811-817. (in Chinese)

[12] Wang X P, Yang J S, Yao R J, Yu S P. Irrigation regime and salt dynamics for rice with brackish water irrigation in coastal region of North Jiangsu Province. Transactions of the CSAE, 2014; 30(7): 54-63. (in Chinese)

[13] Yang J G, Huang G H, Ye D Z, Xu X, Wang J, Huang Q Z, et al. Saline water irrigation management for spring wheat in the Yellow River Irrigation District of Ningxia. Transactions of the CSAE, 2010; 26(4): 49-56. (in Chinese)

[14] Yang S Q, Ye Z G, Shi H B, Lan Y T. Simulation and prediction of rotational irrigation with salty and fresh water in the Hetao irrigation area of Inner Mongolia. Transactions of the CSAE, 2010; 26(8): 8-17. (in Chinese)

[15] Ma Y, Feng S Y, Song X F. Evaluation of optimal irrigation scheduling and groundwater recharge at representative sites in the North China Plain with SWAP model and field experiments. Computers Electronics Agriculture, 2015; 116: 125-136.

[16] Qureshi A S, Ahmad W, Ahmad A F A. Optimum groundwater table depth and irrigation schedules for controlling soil salinity in central Iraq. Irrigation and Drainage, 2013; 62(4): 414-424.

[17] Doorenbos J, Kassam A H. Yield response to water. FAO Irrigation and Drainage Paper 33, FAO, Rome, Italy, 1979.

[18] Van D J C, Huygen J, Wesseling J G, Feddes R A, Kabat P, Walsum P E V, et al. Theory of SWAP Version 2.0.Simulation of water flow, solute transport and plant growth in the soil-water-atmosphere-plant environment. Wageningen: Wageningen Agricultural University and DLO Winand Staring Centre, 1997; pp.19-114.

[19] Chen B, Yang X, Zhao J K. Planting technology for great yield of summer maize at Guanzhong District, Shaanxi Province. Modern Agricultural Science and Technology, 2013; 5: 48-48. (in Chinese) 